\title{
Emission Control of Trace Heavy Metal Elements in Coal-fired Power Plants
}

\author{
Debo $\mathrm{Li}^{1}$, Qisheng $\mathrm{Xu}^{1}$, Cao Xin ${ }^{2}$, Xudan Ren ${ }^{2}$, Jianyi $\mathrm{Lu}^{2 \star}$ \\ ${ }^{1}$ Electric Power Research Institute of Guangdong Power Grid co., Ltd., Guangzhou, 510080, \\ Guangdong, P.R.China \\ ${ }^{2}$ School of Environmental Science and Engineering, North China Electric Power University, \\ Baoding, 071003, Hebei, P.R.China. \\ *corresponding author email: lujianyi@tsinghua.org.cn
}

Keywords: Coal-fired power plants; Arsenic; Selenium; Lead; Emission control

\begin{abstract}
The trace heavy metal elements occur in coal during the coal-forming process and enrich on the bottom ash or fly ash after coal combustion, then escape into the air in the form of particulate or vapour, causing certain environmental hazards. In this paper, control methods for three important trace heavy metal elements, $\mathrm{As}, \mathrm{Pb}$, and $\mathrm{Se}$, which were defined as hazardous air pollutants (HAPs) in CAAA, are compared and classified, the emissions control technologies can be mainly implemented by the pre-combustion processing, the in-combustion processing, and the postcombustion processing as well as other aspects. In view of different elements, the corresponding removal methods are proposed.
\end{abstract}

\section{Introduction}

At present, nearly all elements in the earth's crust are detected in coal. The content of trace element is lower than $100 \mu \mathrm{g} / \mathrm{g}$, such as As, Cr, Se, Cu, Pb, Zn, Hg, etc., which were defined as hazardous air pollutants (HAPs) in CAAA. The trace metal elements in coal occur during coal formation, transportation and transformation in the process of combustion, after complicated physical and chemical actions, redistribute in fly ash particles, which have different particle sizes and show different enrichment characteristics. Trace elements emitted from coal combustion have become an increasingly important environmental concern, due to its potential threats to human health, global agriculture and social sustainability. Among the toxic metals of interest are most volatile trace elements, which could not be easily removed in air pollutants control equipments, which escape into the air as direct atmosphere emission [1].

According to the trace elements' volatility and enrichment in the process of combustion, elements are generally divided into three categories: the first kind mainly enriched in the bottom ash of coarse particle, or uniform distributed in the bottom ash and fine fly ash; the second category is trace elements, which volatilize in the combustion process, when temperature decrease, trace elements condense after leaving the combustion zone. These elements are easy to concentrate on fine particles and the capture efficiency of dust removal device for these particles is very low. The third type of trace elements is more volatile, they basically don't exist in the solid phase, final emissions escape into the atmosphere in gas phase [2]. Although the content of trace element in coal is very low, but the annual emissions should not be ignored, emissions of trace element caused by human factors account for $40 \sim 85 \%$ of total quality [3], which becomes adverse factors to the human survival environment and human health. 


\section{Study methods}

Trace heavy metal elements released from coal at high temperatures, after carbureting, part of them exist in gas state, in the cooling process of flue gas, steam forms a small aerosol nuclear, then, coagulates and enriches surrounding ashes, the number of condensation has a lot to do with the size of the dust specific surface area and the volatility of trace element, volatility is related to its form, combustion condition (mainly are temperature and atmosphere), and other factors; specific surface area has relation to the dust size and pore structure characteristic. All of these factors show the characteristic of physical adsorption. Besides, ash also has chemical adsorption for trace elements. This is because ashes contain a variety of mineral components and some trace elements, these mineral components start chemical reactions with trace elements vapors in a certain temperature, and adsorb on ashes in a new compound [4]. In this paper, control methods of important trace heavy metal elements, $\mathrm{As}, \mathrm{Pb}$, and $\mathrm{Se}$, for coal-fired power plants are investigated and reviewed, and removal methods of heavy metal elements are classified and proposed.

\section{Discussion and Suggestions}

In order to reduce the emissions of heavy metals, the following points should be considered: reducing the concentration of trace elements in coal; abating the formation of submicron particles; decreasing emissions of particulate matters and so on. According methods and techniques were then put forward to control the emission of trace elements in flue gas for coal fired power plants during the processes of before, in and after the combustion.

\section{As removal}

In nature, As rarely exists in the elemental state, usually in combination with sulfur, such as orpiment $\left(\mathrm{As}_{2} \mathrm{~S}_{3}\right)$, realgar $\left(\mathrm{As}_{4} \mathrm{~S}_{4}\right)$, etc. In China, the average As content in coal is $4.7 \mathrm{~g} / \mathrm{t}$, which is slightly lower than the world average. An experiment was done on the determination of As concentration in coal samples, results are shown in Table 1. Coal is the main source of As in atmosphere, after combustion, As mainly distribute in four kinds of carriers, namely, slag, bottom ash, fly ash and fine fly ash, fine fly ash is discharged into the atmosphere. The enrichment concentration of As in fly ash is higher than in bottom ash and slag [5], with the enrichment concentration increases, the fly ash particle size decreases.

Table 1: Arsenic contents of fly ash in different combustion condition

\begin{tabular}{|c|c|c|c|c|}
\hline \multicolumn{2}{|c|}{ Sample } & $\begin{array}{l}\text { Fly ash } \\
\text { (ppm) }\end{array}$ & $\begin{array}{l}\text { Bottom ash } \\
\text { (ppm) }\end{array}$ & $\begin{array}{l}\text { Emission load } \\
\text { (ppm) }\end{array}$ \\
\hline Datong & 850 & 1.3078 & 3.0282 & 4.336 \\
\hline \multirow[t]{2}{*}{ bituminous coal } & $1100{ }^{\circ} \mathrm{C}$ & 3.7282 & 1.229 & 4.9572 \\
\hline & 1250 & 7.3842 & 4.4082 & 11.7924 \\
\hline Liupanshui & $850{ }^{\circ} \mathrm{C}$ & 11.5202 & 8.3642 & 19.8844 \\
\hline \multirow[t]{2}{*}{ bituminous coal } & $1100{ }^{\circ} \mathrm{C}$ & 12.7042 & 7.6362 & 20.3404 \\
\hline & 1250 & 14.9442 & 5.8402 & 20.7844 \\
\hline Xiaolongtan & $850{ }^{\circ} \mathrm{C}$ & 14.1888 & 7.9968 & 22.1856 \\
\hline \multirow[t]{2}{*}{ lignite } & $1100{ }^{\circ} \mathrm{C}$ & 27.0008 & 8.8368 & 35.8376 \\
\hline & $1250{ }^{\circ} \mathrm{C}$ & 27.1328 & 7.9208 & 35.0536 \\
\hline
\end{tabular}

i) Pre-combustion processing

The pre-treatment before combustion mainly refers to the coal processing technology, which includes flotation method, chemical method; generally, by increasing the combustion efficiency of coal and reducing flue gas emissions to reduce As pollution levels. Technology of removing As before burning is mainly for coal washing. According to studies, in the process of coal washing, the removal rate of inorganic As in coal is above 70\%. For organic As, if using traditional coal washing, 
As is enriched; therefore, such minerals in coal don't have good separation methods.

ii) In-combustion processing

In the combustion process, adding solid adsorbent (such as kaolin, limestone, bauxite, etc.) can effectively control the emissions of As. Adsorbent in addition to adsorb of As vapour, also adsorb of As metal particles and molten ashes. At present, the using form of adsorbent basically has 3 kinds: spraying into the furnace or tail flue in the form of powder; using of flue gas circulating fluidized bed; mixing adsorbent with coal well before burning [6,7].

Technology of spraying calcium into the furnace is feasible of removing As during combustion. Studies show that adding $\mathrm{CaO}$ has strong inhibitory effect on the volatility of As in coal; the removal efficiency is $40 \%$. While taking the circulating fluidized bed boiler burns coal, particles in the bed have fine flowability, $\mathrm{CaO}$ maximize reacts with As, and stay in boiler for a longer time, therefore, the inhibitory effect of $\mathrm{CaO}$ for As volatility is obvious than that in fixed bed, the removal efficiency can reach $80 \%$.

iii) Post-combustion processing

Emission control after combustion mainly uses air pollutants control equipments (APCDs) and various desulfurization and denitrification equipments for As removal in flue gas.

Firstly, people should improve the efficiency of dust removal. Study shows that for As in fly ash, the removing efficiency of ESP is 4.3 times than scrubber. Therefore, improving the dust removal efficiency is the direct method to reduce As emissions, in order to meet the control requirements, it is necessary to appropriate transform the existing pollution control devices. For example, adding electric coagulation device in front of precipitator is beneficial to capture As of fine fly ashes. In addition, we can also use electrostatic-bag precipitator, bag filter and other high efficiency dust removal equipments. The second method is chemical, this method mainly includes: sodium sulfide method, using wet desulfurization devices to remove As. $\mathrm{As}^{2+}$ is soluble in water, and the temperature of flue gas desulfurization system is relatively low, which is conducive to the absorption of bivalent As and the oxidation of element As, in the wet flue gas desulfurization system, either using lime or limestone as absorbent, both of them can remove As. The third is absorbent method, As can attach to ash, the basic principle of absorbent method is capturing fine fly ashes, such as activated charcoal method.

Basically, removing after combustion makes the theoretical As removal efficiency reach more over $90 \%$, all of these three methods have good prospect of industrial application.

\section{Pb removal}

The average of $\mathrm{Pb}$ level in Chinese coal is 23.32ug/g, $\mathrm{Pb}$ pollutants emitted from coal-fired power plants in 2010 was about 40000 tons. PeiBing calculated the annual lead emissions amount of coal-fired power plants, the change tendency is shown in Fig.1. Due to an increase in the amount of coal, the national lead emissions of coal-fired power plants increased in 1990-2011, the discharge of lead emission was 126.67tons in 2011. Lead in fuels of coal-fired power plants is differ, and most power plants didn't install wet desulphurization device in early years, so the actual emissions may be higher than the calculated value[8]. $\mathrm{Pb}$ in coal is released into gas after combustion, during the process of continuous cooling, $\mathrm{Pb}$ in flue gas experiences a series of physical and chemical changes, part of them adsorb or condense on the surfaces of fly ash particles to form $\mathrm{Pb}_{\mathrm{p}}$; some of $\mathrm{Pb}$ react with other ingredients in flue gas to form water soluble compounds, that is water-soluble $\mathrm{Pb}^{2+}$, or water-insoluble $\mathrm{Pb}^{0}$, both of them are known as $\mathrm{Pb}_{\mathrm{g}}$.

Almost all of coal-fired power plants in China have installed electrostatic precipitators, bag filters, or electric-bag dust collectors, and the dust removal efficiency increases significantly; $90 \%$ of power plants have adopted the wet limestone-gypsum method, sea water process, flue gas circulating fluidized bed or ammonia desulphurization devices; only a few power plants have installed the SCR denitration devices. These devices have synergy reduction effect on $\mathrm{Pb}$ in the flue gas, for example, dust removing devices can remove particulate $\mathrm{Pb}$, and the wet limestone-gypsum desulphurization devices synergistic remove part of $\mathrm{Pb}_{\mathrm{g}}$. Thus, $\mathrm{Pb}$ in flue gas migrates into fly ash, desulphurization gypsum and desulfurization wastewater. Detailed data are shown in Table 2, in the 
test, the 2\# boiler adopts dry desulphurization technology in circulating fluidized bed, 1\# and 3\# boilers both adopt the wet limestone-gypsum desulphurization technology; 3\# boiler installs bag filter, $1 \#$ and 2\# boilers install electrostatic precipitator. Seen from the table, after the flue gas purification device, the concentration of particulate $\mathrm{Pb}$ is significantly lower, the removal efficiency of bag filter is higher than that of electrostatic precipitator, precipitators also have a certain effect on removing gaseous $\mathrm{Pb}$. The wet limestone-gypsum method has a synergy removal effect for $\mathrm{Pb}$ in the flue gas, and also has a certain synergy effect for particulate $\mathrm{Pb}$, the average removal efficiency is $34.48 \%$ [9].

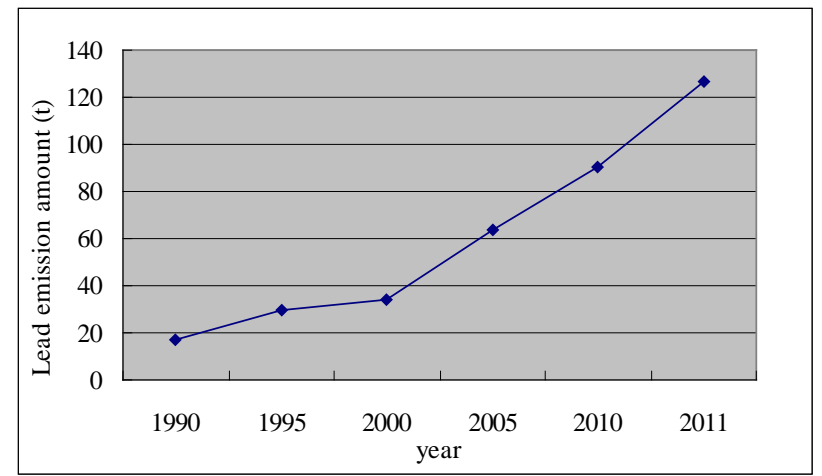

Fig.1. Lead emission amount of coal-fired power plant in China from 1990 to 2011

Table 2. Effect of the APCDs on the distribution and speciation of $\mathrm{Pb}$ in flue gas

\begin{tabular}{ccccc}
\hline $\begin{array}{c}\text { Boiler } \\
\text { number }\end{array}$ & $\begin{array}{c}\text { State of } \\
\mathrm{Pb} \text { in flue gas }\end{array}$ & $\begin{array}{c}\text { ESP } \\
\text { removal } \\
\text { efficiency } \\
(\%)\end{array}$ & $\begin{array}{c}\text { Desulphurization } \\
\text { device } \\
\text { removal efficiency } \\
(\%)\end{array}$ & $\begin{array}{c}\text { Total } \\
\text { removal } \\
\text { efficiency } \\
(\%)\end{array}$ \\
\hline 1 & particulate & 95.61 & 63.35 & 97.99 \\
& gaseous & 58.52 & 88.51 & \\
2 & total & 90.96 & 77.81 & 96.31 \\
& particulate & 97.00 & - & \\
& gaseous & 91.97 & - & 98.19 \\
& total & 96.31 & - & \\
& particulate & 97.19 & 39.22 & \\
& gaseous & 87.36 & 80.62 & \\
& total & 95.85 & 56.38 & \\
\hline
\end{tabular}

\section{Se removal}

Selenium is volatile, the volatilization rate of selenium is higher with the increasing temperature, in the combustion process, Se is released mainly in the form of toxic $\mathrm{SeO}_{2}$ and so on, they have great harm to the environment, and bring difficulty for controlling selenium discharges. It is estimated that the annual emissions in coal-fired power plant is 195 tons. Most scholars say the average mass fraction of Se in Chinese coal is $4 \sim 5 \mathrm{mg} / \mathrm{kg}$, which is higher than the world average of $3 \mathrm{mg} / \mathrm{kg}$. Analysis results show that the proportion of Se in slag, fly ash of filter, fine fly ash and flue gas is $11.2 \%, 71.3 \%, 1.1 \%$ and $11.2 \%$ respectively. Control measures in coal-burning mainly have the following several kinds [10]. 


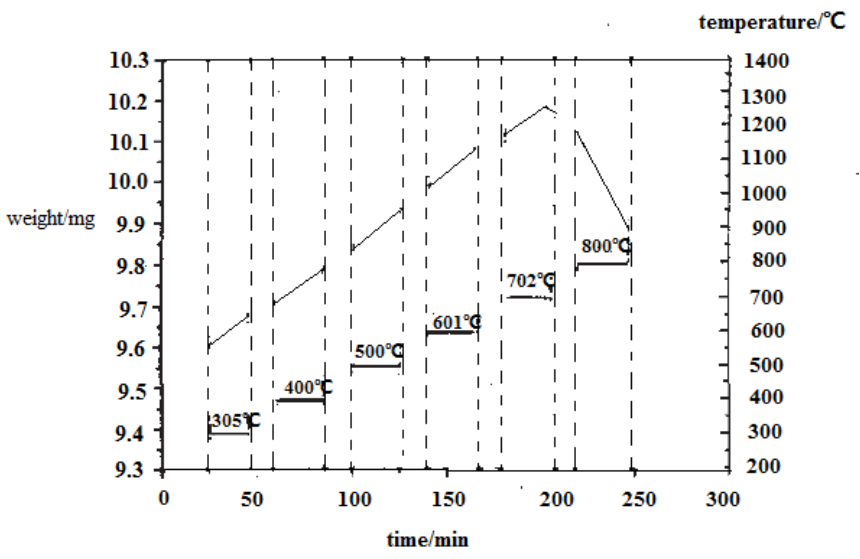

Fig. 2. Se fixation effect of $\mathrm{CaO}$ at the temperature of $300-800^{\circ} \mathrm{C}$

i) Pre-combustion processing

The conventional coal washing can remove part of Se before burning. Research suggests that through industrial coal preparation, the Se removal rate was $0 \sim 80 \%$, mostly was below $50 \%$. According to researches, conventional coal preparation can reduce the mass fraction of Se in coal by $14 \% \sim 34 \%$, and the removal efficiency of this process mainly depends on the organic affinity of Se and the washability of coal in pyrite, the removal efficiency is higher with high Se.

ii) In-combustion processing

When arsenic exists in coal in organic combining state (organic arsenic), using conventional coal washing and coal preparation technology is hard to remove it, so, people can add some additives (arsenic fixing agents) before combustion to reduce the environmental impact of arsenic in coal.

Studies found that, $\mathrm{CaO}$ can restrain the volatilization of Se in coal, the chemical reaction mechanism is $\mathrm{CaO}(\mathrm{s})+\mathrm{SeO}_{2}(\mathrm{~g}) \rightarrow \mathrm{CaSeO}$ (s); some scholars did contrast test that $\mathrm{CaO}$ adsorb $\mathrm{SeO}_{2}$ in the temperature of $300 \sim 800^{\circ} \mathrm{C}$, as shown in Fig.2. As we can see, in $300 \sim 700^{\circ} \mathrm{C}$ range, slopes are basically the same, it shows that in this range, the adsorption ability of $\mathrm{CaO}$ is little affected by temperature. At $800^{\circ} \mathrm{C}$, the weight curve is falling, which verifies the adsorption of $\mathrm{SeO}_{2}$ is analytical at $800^{\circ} \mathrm{C}$ [11]. Continue doing this test, got that the optimum temperature of $\mathrm{CaO}$ desulfurization at the same time to take off Se is $700 \sim 740^{\circ} \mathrm{C}$.

iii) Post-combustion processing

The main method is using solid adsorbent. The using way is roughly same with arsenic removal, including that: (1) flue gas flows through the fixed bed or fluidized bed; (2) directly injects powder solid adsorbent to flue gas. Adsorbent includes clay minerals, metal oxide and $\mathrm{Ca}(\mathrm{OH})_{2}$, etc. Some scholars studied the removal effect of activated carbon on Se in flue gas, results showed that, $12 \% \sim 19 \%$ of Se can be captured by activated carbon. On the activated carbon surfaces, physical adsorption and chemical adsorption proceed at the same time, the capture efficiency is related to the types of activated carbon and the composition of flue gas.

\section{Conclusion}

Heavy metals released by coal-fired power plants mainly exist in the form of gas in the environment atmosphere, they can migrate for long distances and stay for a long time, these pollutants are global, thus, positive control measures must be taken. Effective paths to control the release of trace elements include pre-combustion, in-combustion and post-combustion. For the removing of As in coal, the domestic is still in its infancy stage, using of existing equipments for transformation is the most closest method to industrial application. Thus, people should limit the using and the mining of high selenium stone coal; develop effective coal washing techniques, fixing agents and develop flue gas solid adsorbents at the same time, etc. In recent years, coal-burning power plants release $\mathrm{Pb}$ into the atmosphere reduces in China, this is mainly due to the strict control of regular atmospheric pollutants, along with the execution of new standard for air pollutants, especially for particulates limit, normal atmospheric $\mathrm{Pb}$ emissions of coal-fired power plants are 
expected to further reduce. But China has large coal base figure, the public still need to pay more attention to atmospheric emissions of trace heavy metals in coal-fired power plants.

\section{References}

[1] Guo Xin. Emission and control research of mercury, arsenic and selenium in the process of coal combustion[D]. Huazhong University of Science and Technology, 2005.

[2] Jia Xiao-hong, Guo Xin, Zheng Chu-guang. Speciation analysis of trace elements in coal combustion process [J]. Coal Conversion, 2003, 26(1): 17-21.

[3] Nraigu J O. A global assessment of natural sources of atmospheric trace metals [J]. Nature, 1989, 338: 47-49.

[4] Xu Lu-si, Cheng Jun-feng, Zeng Han-cai. Study On absorption removal of trace heavy metals by using fly ash from coal combustion [J]. Thermal Power Generation. 2004, (4):10-13.

[5] Wang Chun-mei. Experiment research of the generation and control of ultrafine particles in coal combustion [D]. Huazhong University of Science and Technology, 2004.

[6] Zhao Yi, Xue Fang-ming. Research status of arsenic removal technology in coal-fired boilers [J]. Electric power technology and environmental protection, 2010, 26(1): 25-27.

[7] Yan Pei. Arsenical Transform and control technology in the process of coal-fired power plant [D]. North China Electric Power University, 2006.

[8] Pei Bing. Field measurement for lead emission in the plumes of coal-fired power plants [J]. Acta Scientiae Circumstantiae, 2013, 33(6): 1697-1702.

[9] Deng Shuang, Zhang Fan, Liu Yu, etc. Lead emission and speciation of coal-fired power plants in China [J]. China Environmental Science, 2013, 33(7):1199-1206.

[10] Tian He-zhong, Qu Yi-ping, Wang Yan, etc. Emission and control of atmospheric selenium from coal combustion in China [J]. Electric power, 2008, 42 (8): 53-57.

[11] Li Yu-zhong, Tong Hui-ling, Zhuo Yu-qun, etc. Experimental study on simultaneous removal of sulfur and trace selenium element [J]. Journal of engineering thermophysics, 2006, 27: 223-226. 